\title{
Applied ontology: The next decade begins
}

\author{
Nicola Guarino ${ }^{\mathrm{a}}$ and Mark Musen ${ }^{\mathrm{b}}$ \\ ${ }^{\text {a } I S T C-C N R}$ Laboratory for Applied Ontology, Trento, Italy \\ ${ }^{\mathrm{b}}$ Stanford University, Stanford, CA, USA
}

In 2005, IOS Press published the first issue of Applied Ontology. At the time, we argued that, at the core of the journal, there was "a desire to understand the nature of reality and how people construe their world". We declared that ontology was both "fundamental to human thought" and "to translating our thoughts into computational artifacts" (Guarino \& Musen, 2005). With an editorial board of distinguished scholars representing the fields of computer science, informatics, information science, philosophy, linguistics, psychology and social science, we had the firm belief that Applied Ontology would fulfill an important academic niche, becoming an essential forum for discussion on topics such as ontological analysis, conceptual modeling, and the role of domain models in building and managing information systems.

The facts now show that we were correct. More than one hundred papers later, we can claim that Applied Ontology has published some of the most cited articles in formal ontology, ontology-based information systems, Semantic Web technology and ontology engineering. We viewed the launch of the journal as a kind of experiment, and we are gratified that the community has responded so positively to Applied Ontology as a venue in which to share and discuss its ideas.

In the first issue of the journal, we noted that, "ten years ago, academic workers in computer and information science spoke of ontology carefully and cautiously, almost embarrassed to utter the 'o' word" (Guarino \& Musen, 2005). Although the notion of applied ontology certainly had taken root by that time, here we are - ten years later - and applied ontology has become entrenched in nearly everything that we do.

Nearly each of us now carries a smartphone (a commodity that did not exist in 2005) that supports a virtual personal assistant such as Siri. Siri, as it existed at the time when the software was acquired by Apple, simply could not have performed its various tasks without explicit ontologies to define the world of movies, restaurants, calendars and personal contacts (Gruber, 2013).

In 2015, we take the notion of artificial intelligence (AI) for granted, so much so that the lay press no longer speculates about whether AI is even possible, but instead emphasizes the implications for society as AI becomes increasingly sophisticated and potentially the object of malevolent use (Kohli, 2015). None of this widespread concern and fascination with AI was imaginable in 2005 - years before the stunning success of IBM's Watson system playing the game Jeopardy! was broadcast live around the world, captivating the imaginations of millions of ordinary people. Watson, of course, relies on a variety of technologies to achieve its impressive performance (Ferrucci et al., 2010), but ontologies play an essential role in driving the program's text-processing and information-retrieval activities. In the 
future, ontologies undoubtedly will contribute to increasing the transparency of intelligent systems and ultimately - to enhancing the social accountability of AI.

Since 2005, important domain-specific ontologies have emerged in multiple fields, becoming official or de facto standards, with huge impact on the communities that they serve. Just to mention a few examples, the Gene Ontology (Ashburner et al., 2000) has exploded in its importance to biology, providing the basis for interpreting a wide range of high-throughput experiments in the life sciences (Khatri et al., 2012). The World Health Organization has chosen to recast the International Classification of Diseases which has roots in a lexicon developed in the 19th century - as a formal ontology, with explicit term definitions and relationships (Tudorache et al., 2010). In the business sector, the Resources, Events, Agents Accounting Model (REA; McCarthy, 1982) - discussed in the current issue by Hunka and Zacek (2015) - after decades of evolution, has become an ISO standard ontology. The more recent Financial Industry Business Ontology (FIBO; Bennett, 2013) has been recognized by the Object Management Group. We also have seen the standardization of ontologies in the manufacturing domain (PSL, Process Specification Language; Gruninger \& Menzel, 2003), in process and production industries (Batres et al., 2007), and recently in the robotics domain (ORA, Core Ontology for Robotics and Automation; IEEE, 2015). In the humanities, the International Council of Museums' Committee on Documentation Conceptual Reference Model (CIDOC CRM; Doerr, 2003) is now an ISO standard, resulting from an ontological harmonization of previous resources used for describing the collections of museums and digital libraries. On the Web, all major search engines, including Bing, Yahoo!, Google and Yandex, have adopted schema.org (2015) as a comprehensive mechanism to index Web pages. Finally, we have seen the rise of the Internet of Things and the need for new ontologies to enable people and devices to communicate with one another online (Gaglio \& Lo Re, 2014).

Since 2005, ontologies have become an important element in the strategic digital agenda of several governments, not only as an instrument to effectively exploit open data for semantic interoperability, but also as a means to achieve more complete, unambiguous definitions for legally binding terminology. The United States Treasury's Office of Financial Research, for example, in the context of initiatives in response to the 2008 Wall Street financial crisis, has recently recommended the adoption of ontologybased conceptual models as standardized and extensible binding legal definitions of derivative contracts (OFR, 2014) - one of the explicit goals of FIBO (Bennett, 2013).

Of course, the level of sophistication of these ontologies varies quite a bit, from lightweight ontologies mainly focusing on machine interoperability (where the meaning of terms is more or less known in advance), to reference ontologies that carefully aim to avoid misunderstandings among humans, to foundational ontologies that provide the basic common vocabulary for conceptual modeling and ontological analysis. Since its beginning, our journal has been focusing mainly on the latter two kinds of ontologies, carving out a previously unexplored research niche where what matters most is the content, not the representation. As we stressed in our first editorial, this focus for our research is intrinsically interdisciplinary, and yet it is acquiring more and more its own shape, to the point that - perhaps - a new science is emerging. For sure, we can point now to a body of accumulated results, in terms of formal theories, methodologies and experiences, which increasingly are forming a coherent whole. We do not have space in this editorial to properly account for all this work, but we are planning to celebrate the journal's anniversary year with a number of state-of-the-art and visionary articles complemented with short position papers from scholars coming from different disciplines.

Meanwhile, our research community has become more organized. Since we began to publish Applied Ontology, the International Association for Ontology and its Applications (IAOA) has been incorporated and its membership has been growing. The IAOA has been a strong supporter both of our journal and of 
the biannual conference on Formal Ontology in Information Systems (FOIS). Since 2006, with support from the Ontolog Community, the U.S. National Institute of Standards and Technology, and now from IAOA and other organizations, an annual Ontology Summit has explored in depth special topics of importance to the international ontology community (Ontolog, 2015).

As we anticipate the next ten years of our journal, we expect to be publishing papers that describe the uptake and use of ontologies in new application domains, that propose enhanced approaches to understanding and modeling the phenomena that our ontologies attempt to capture, and that present new technologies to assist the engineering and dissemination of ontologies and the incorporation of ontologies within information systems.

Our future work, and the work that we celebrate with the publication of this tenth-anniversary issue, reflects the talent, creativity and industriousness of our research community. More than anything, the success of our journal depends on the authors who submit their work to us for publication. The caliber of any journal is always a function of the quality of the work that it distributes, and we are grateful for the many outstanding papers that we receive. In the case of Applied Ontology, the quality of those papers certainly is enhanced by the careful attention of our reviewers, who work astutely and diligently to help our authors to improve their manuscripts, and by our editorial board, who critique submissions and who ensure that each paper is refereed by the best possible set of reviewers. With this issue of the journal, we are appointing a group of associate editors, who will help the editorial team to manage the review process more efficiently. We remain very grateful to our publisher, IOS Press, to everyone associated with the editorial process, and to the members of the scientific community who submit their papers to our journal for making this ten-year odyssey possible.

A decade ago, we predicted that we were about to see a radical transformation in the role of ontology in our society. That transformation clearly seems to be taking place, and in a way that makes ontologies blend in into the background, rather than to call attention to themselves when we interact with the information systems that surround us every day. Our assessment in 2005 is only more true now: "With links to a vast philosophical tradition, to nuances in human language and cognition, and to emerging methods for building the information systems that will affect the future of our society, the study of ontology has never been more important" (Guarino \& Musen, 2005). Our collective success both in making theoretical advances and in translating our results into practical applications makes our field extremely exciting. It is a privilege for Applied Ontology to be able to serve the scientific community. It is thrilling to be able to play a role in creating the foundation that will enhance society with improved methods for ontological modeling and with new kinds of information technology that can put the resulting models to use.

\section{References}

Ashburner, M., Ball, C.A., Blake, J.A., et al. (2000). Gene ontology: Tool for the unification of biology. Nature Genetics, 25(1), 25-29.

Batres, R., West, M., Leal, D., Price, D., Masaki, K., Shimada, Y., Fuchino, T. \& Naka, Y. (2007). An upper ontology based on ISO 15926. Computers and Chemical Engineering, 31, 519-534.

Bennett, M. (2013). The financial industry business ontology: Best practice for big data. Journal of Banking Regulation, 14, 255-268.

Doerr, M. (2003). The CIDOC conceptual reference module. An ontological approach to semantic interoperability of metadata. AI Magazine, 24(3), 75-92.

Ferrucci, D., Brown, E., Chu-Carroll, J., et al. (2010). Building Watson: An overview of the DeepQA project. AI Magazine, 31(3), 59-79.

Gaglio, S. \& Lo Re, G. (Eds.) (2014). Advances Onto the Internet of Things: How Ontologies Make the Internet of Things Meaningful. Heidelberg: Springer. 
Gruber, T.R. (2013). Nature, nurture, and knowledge acquisition. International Journal of Human-Computer Studies, 71(2), 191-194.

Gruninger, M. \& Menzel, C. (2003). Process specification language: Principles and applications. AI Magazine, 24, 63-74.

Guarino, N. \& Musen, M.A. (2005). Applied ontology: Focusing on content. Applied Ontology, 1(1), 1-5.

Hunka, F. \& Zacek, J. (2015). A new view of the REA state machine. Applied Ontology, 10(1), 25-39 (this issue).

IEEE (2015). 1872-2015 - IEEE approved draft standard for ontologies for robotics and automation. Available at: http:// standards.ieee.org/findstds/standard/1872-2015.html. Accessed 7 April 2015.

Khatri, P., Sirota, M. \& Butte, A.J. (2012). Ten years of pathway analysis: Current approaches and outstanding challenges. PLoS Computational Biology, February 23, 2012. doi:10.1371/journal.pcbi.1002375.

Kohli, S. (2015). Bill Gates joins Elon Musk and Stephen Hawking in saying artificial intelligence is scary. Quartz, 30 January 2015. Available at: http://qz.com/335768. Accessed 29 March 2015.

McCarthy, E.W. (1982). The REA accounting model: A generalized framework for accounting systems in a shared data environment. Accounting Review, 52(3), 554-578.

OFR (2014). Summary minutes of the Department of the Treasury Office of Financial Research (OFR) Financial Research Advisory Committee. Public Meeting, July 24, 2014. Available at: http://financialresearch.gov/frac/files/FRAC_ Meeting_Minutes_07-24-2014_FINAL.pdf.

Ontolog (2015). Ontology summit. Available at: http://ontolog.cim3.net/cgi-bin/wiki.pl?OntologySummit. Accessed 29 March 2015.

Schema.org (2015). Available at: http://schema.org. Accessed 29 March 2015.

Tudorache, T., Falconer, S., Nyulas, C., et al. (2010). Will Semantic Web technologies work for the development of ICD-11? In Proceedings of the International Semantic Web Conference (ISWC 2010). Lecture Notes in Computer Science (Vol. 6497, pp. 257-272). Heidelberg: Springer. 